\title{
The Relationship of Social Justice Beliefs to Environmental Attitudes among Students at a Private University
}

\author{
Trish A. Vandiver \\ Department of Psychology, University of St. Thomas, USA
}

Copyright $\odot 2016$ by authors, all rights reserved. Authors agree that this article remains permanently open access under the terms of the Creative Commons Attribution License 4.0 International License.

\begin{abstract}
The goal of the present study was to examine the relationship of social justice beliefs, gender, religiousness, and ethnicity on environmental attitudes among college students at a private university. Participants in the current research with higher scores on social justice measures also had higher scores on three environmental measures: attitudes toward the environment, conscientiousness about the environment and involvement in environment issues. Gender, race/ethnicity, and college major were not found to be statistically significant. Future research should examine the role of social justice beliefs on environmental attitudes in more general populations of college students.
\end{abstract}

Keywords Social Justice, Environment, Attitudes, Students, Private University

\section{Introduction}

Psychology naturally overlaps with social justice, particularly in such domains as human rights and mental health [1]. However, the intersection of social justice with environmental issues in psychology has been less fully examined. If, as research has suggested, healthy environments help promote positive outcomes such as lowered aggression, increased self-discipline, improved perceptions of health status, and even lower levels of road $[2,3,4,5,6,7,8,9,10]$ then it stands to reason that psychologists should address environmental initiatives in the context of social justice.

In contrast to healthy outcomes, unhealthy environmental outcomes adversely affect physical and mental health status, unfairly producing more negative mental health results for some groups as compared to others. Environmental factors that affect quality of life have ethical implications for psychologists because the inequitable distribution of unhealthy environments falls most heavily on individuals of lower social status. Noise, chemical exposure, and unhealthy housing locations disproportionately affect low income individuals. Psychology's ethical principles make it imperative that environmental and social justice issues be jointly addressed $[11,12,13,14,15]$.

If environmental issues are to be tackled by psychologists, then making psychologists-in-training cognizant of these concerns becomes imperative. One way to make environmental concerns more relevant to college-age students is to connect students' beliefs about environmental initiatives to students' own local environments $[16,13]$.

Short-term interventions have often been initiated to produce environmentally aware behaviors. It has been shown that interventions with college students can result in increased environmentally friendly behaviors such as recycling [17], but maintaining such behaviors over time is a more complex process than was once thought. Increased access to information is not sufficient; focusing on intra-personal factors appears to be required if changes in behavior are to be maintained over time. Intra-individual variables such as personality and attitude characteristics appear to be important contributors to lasting changes in environmentally-friendly behaviors [18, 19]. Involvement in and conscientiousness about environmental issues have been associated with demographic factors such as gender and one's academic major [20,21]. Establishing more clearly which intra-personality factors contribute to positive environmental attitudes may be important to both producing and maintaining permanent changes in behavior.

Environmentally responsible behaviors may be conceptualized in terms of social justice. Pope Francis in his encyclical, Saudato $\mathrm{Si}^{\prime}$ [22], is devoted to environmentalism. Students at a Catholic university should be particularly sensitive to environmental issues as a result. Students with a deep commitment to social justice issues may be more likely to maintain environmentally-friendly behaviors over time if social justice and environmental factors are connected for them. One such effort to unify these factors, Education for 
Sustainable Development, has sought to combine concerns about climate change and other human equality and social justice issues in a multi-sector learning environment [23]. Approaches that combine relevant personal factors, social justice awareness, and environmental concerns may increase the relevance of these combined issues for young people so that environmentally-friendly behaviors may be more likely to continue over time.

The research presented here examined the association of social justice with environmental attitudes among college students attending a private religious school as a first step in determining if increased social justice awareness is associated with environmental awareness. It was hypothesized that there would be a relationship between the social justice measures and the environmental measures. It was predicted that students who scored higher on social justice measures would also endorse more environmentally-friendly attitudes. It was further hypothesized that there would be an association between social justice awareness and higher scores on measures of students' involvement in and consciousness about environmental issues. It is argued that if students connect commitment to social justice with concern with environmental issues, then they may be more willing to commit to environmentally friendly behaviors.

\section{Method}

\section{Participants}

Participants were 192 students at a small private Catholic university in Houston, TX. As is common for the Psychology Department at this university, the majority of participants were age 21 and younger $(65.1 \%$; considered traditional college age) and female (77.6\%). Ethnicities were white non-Hispanic, Hispanic, and Asian, with a small percentage of African American students. The majority $(82.9 \%)$ identified themselves as traditionally religions (either Catholic or Protestant). See Table 1 for frequencies, means, and standard deviations for the demographic variables.

Table 1. Number and percentage for demographic variables

\begin{tabular}{|c|c|c|}
\hline Variable & $\mathrm{n}$ & $\%$ \\
\hline \multicolumn{3}{|l|}{ Gender } \\
\hline Female & 149 & 77.6 \\
\hline Male & 43 & 22.4 \\
\hline \multicolumn{3}{|l|}{ Age Category } \\
\hline Age 21 or Younger & 125 & 65.1 \\
\hline Older than 21 & 65 & 33.9 \\
\hline \multicolumn{3}{|l|}{ Ethnicity } \\
\hline White non-Hispanic & 64 & 33.0 \\
\hline Hispanic/Latino/Latina & 67 & 34.9 \\
\hline Asian & 48 & 25.0 \\
\hline African American & 13 & 6.8 \\
\hline \multicolumn{3}{|l|}{ Major* } \\
\hline Psychology or joint major with Psychology & 98 & 51.0 \\
\hline Other than psychology & 94 & 49.0 \\
\hline \multicolumn{3}{|l|}{ Religion } \\
\hline Catholic & 130 & 70.8 \\
\hline Not Catholic & 56 & 29.2 \\
\hline
\end{tabular}

Table 2. Means and Standard Deviations for Social Justice Questionnaire subscales, Environmental Awareness Questionnaire, Conscientiousness Question and Involvement Question

\begin{tabular}{|c|c|c|c|}
\hline Variable & $\mathrm{n}$ & $\overline{\mathrm{x}}$ & SD \\
\hline Social Justice Scale: & & & \\
\hline Attitudes & 179 & 65.89 & 11.21 \\
\hline Perceived Behavioral Control & 189 & 28.22 & 5.41 \\
\hline Norms & 191 & 19.32 & 4.78 \\
\hline Intent & 191 & 22.15 & 4.81 \\
\hline Environmental Awareness Scale & 183 & 81.19 & 9.95 \\
\hline Conscientiousness About Environment & 192 & 4.73 & 1.46 \\
\hline Involvement in Environment & 192 & 4.33 & 1.32 \\
\hline
\end{tabular}




\section{Instruments}

Demographic Questionnaire: The demographic questionnaire, created for the study, asked about participants' gender, age, ethnicity, academic major, religion, and magnitude of religious beliefs.

Environmental Awareness Scale (EAS): The Environmental Awareness Questionnaire is a 17-item questionnaire developed by The Office of Environmental Policy to specifically ask about environmental concerns at the University of Connecticut [24] and was modified, with permission, so that it was specific to the campus where the research was conducted. We were given verbal permission to modify and use the questionnaire. Example questions were: "How important is it to you that (school name) purchase recycled and recyclable products?" and "How important is it to you that (school name) considered using fuel-efficient vehicles and alternative fuels to run its vehicles?" Cronbach's alpha for the scale was .80 for our sample. Students were also asked to rate, on a 7-point Likert scale, their involvement with and conscientiousness about environmental issues.

Social Justice Scale (SJS): The Social Justice Scale developed by Torres-Harding, Siers, \& Olson [25] measures social justice awareness along four dimensions: attitudes, perceived behavioral control, norms, and intentions. We were given verbal permission to use the scale. Example items were: "I am confident that I can have a positive impact on others' lives" and "In the future I intend to engage in activities that will promote social justice." Cronbach's alphas were, .96 for attitudes, .90 for perceived behavioral control, .87 for norms, and .90 for intentions for out sample.

\section{Procedures}

Students were recruited in their classrooms and offered extra credit in exchange for participating. Participants were sent a questionnaire packet through a data collection website (SurveyMonkey.com). Questionnaires took about 20 minutes to complete and are described below. The packets were returned anonymously through SurveyMonkey.com.

\section{Analysis}

Because of our interest in demographic factors, one-way ANOVAs were used to examine any relationship with gender, race/ethnicity, college major, and religious affiliation with each of the four subscales of the SJS: attitudes, perceived behavioral control, norms, and intentions. A Pearson Product Moment correlation was used to examine magnitude of participants' religious beliefs with the SJS subscales because it was measured on a 7-point scale. The only statistically significant correlation was between the perceived behavioral control and norms subscales of the SJS and magnitude of religious beliefs perceived behavioral control and norms subscales of the SJS $(\underline{r}=.228, \underline{p}<.01$ and $\underline{\mathrm{r}}=.202, \underline{\mathrm{p}}<.01$ respectively. These variables were not statistically significantly associated with any of the other social justice subscales or with any of the environmental measures.

After ruling out all the demographic variables except sex and age as statistically significant contributors to the environmental measures, a series of regression analyses were conducted to examine the role of the subscales of the SJS as independent variables and each of the three environmental measures as dependent variables (i.e., the total score of the EAS, conscientiousness toward the environment, and involvement in environmental issues). The results of these regressions are reported below.

\section{Results}

\section{Demographic Variables}

Demographic variables, including gender, race/ethnicity, religion, and magnitude of religious beliefs were examined in this research study because of recent interest in demographic variables as predictors of environmentally friendly behavior. There were no statistically significant differences with the social justice subscales (attitudes, behavioral control, norms, intentions) or with the three environmental scales (EAS, conscientiousness, involvement) for academic major or religious orientation although there was a modest correlation with magnitude of religious beliefs and the behavioral control and norms subscales of the SJS. While African American participants had higher scores on both the SJS and the EAS, they made up a very small percentage of participants $(6.8 \%)$ and overall race/ethnicity was not statistically significantly different for either the environment or social justice questionnaire. Psychology majors did not have scores that were statistically significantly different from other majors, and science majors did not have scores that were statistically significantly different from non-science majors. While the majority of students identified themselves as belonging to a traditional religious group (either Catholic or Protestant with $71.4 \%$ identifying as Catholic), specific religious identification was not statistically significantly associated with social justice or environment scores. However, the magnitude of participants' religious beliefs was correlated with the perceived behavioral control and norms subscales of the SJS $(\underline{r}=.228$, $\underline{\mathrm{p}}<.01$ and $\underline{\mathrm{r}}=.202, \underline{\mathrm{p}}<.01$ respectively) as noted above such that students who characterized themselves as more religious on a 7-point scale (with 7 as higher is religiosity) were more likely to score higher on the perceived behavioral control and norms subscales of the SJS. Table 2 reports correlations between the demographic variables and SJS and EAS subscales. Sex was statistically significantly associated with the EAS and was included in the regression analysis model for that variable as was age category based on the general linear model analyses reported below.

\section{Regressions}

A series of linear regression models examined the 
relationship of the social justice subscales with the EAS and conscientiousness about, and involvement in the environment. Means and standard deviations for the dependent variables used in these analyses appear in Table 2 below.

The four subscales of the SJS were treated as independent variables and scores on the EAS, the conscientiousness about the environment question, and the involvement in the environment question were treated as dependent variables in three separate regressions. A general linear model using gender and age category (age 21 and younger and age over 21) resulted in a statistically significant main effect for sex, $\underline{F}$ $(1,180)=17.037, \mathrm{p}<.01$, and an interaction for sex and age, $\underline{F}(1,180)=6.224, \underline{p}=.014$. Therefore sex and age were included in the model for the EAS model. There were no statistically significant results for either sex, age category, or the interaction for sex and age category for either involvement or conscientiousness, so those demographic variables were not included in the models for involvement and consciousness.

The first model used the four subscales of the SJS (norms, perceived behavioral control, attitudes, and intentions and sex and age category) to predict environmental attitude scores on the EAS. The model was statistically significant, $\underline{F}$ $(6,169)=14.878 \mathrm{p}<.001, \mathrm{R}^{2}=.35$. Next, the four subscales of the SJS were used to predict the conscientiousness measure. There was a small but statistically significant effect, $\underline{F}(4,172)=4.581, \underline{p}=.002, R^{2}=.10$. Finally, the four subscales of the SJS were used to predict involvement in environmental activities. Again, there was a small but statistically significant effect, $\underline{\mathrm{F}}(4,172)=4.397, \underline{\mathrm{p}}=.002, \mathrm{R}^{2}$ $=.10$. See Table 3 below for results of these regression models.

Table 3. Correlations between demographic variables and the SJS scales, EAS subscales, Involved and Conscientious

\begin{tabular}{|c|c|c|c|c|c|c|c|}
\hline Variable & EAS & Believe & Behavior Cont. & Norms & Intensions & Involved & Conscientious \\
\hline Sex & $-.291^{* *}$ & .020 & .045 & -.087 & -.037 & .006 & .008 \\
\hline Catholic or not & .023 & .012 & -.050 & -.020 & -.001 & .029 & .013 \\
\hline Race/Ethnicity & -.125 & -.080 & $-.161^{*}$ & .000 & -.072 & .069 & .059 \\
\hline Age (under or over 21) & .090 & -.09 & -.110 & -.033 & -.096 & .063 & .065 \\
\hline Psych major or not & -.142 & -.102 & -.082 & -.085 & -.085 & .063 & .112 \\
\hline
\end{tabular}

$* \mathrm{p}<.01$

$* * \underline{p}<.001$

Table 4. Means and Standard Deviations for Social Justice Questionnaire subscales, Environmental Awareness Questionnaire (EAS), Conscientiousness Question and Involvement Question

\begin{tabular}{|c|c|c|c|}
\hline Variable & $\mathrm{n}$ & $\bar{x}$ & SD \\
\hline \multicolumn{4}{|l|}{ Social Justice Scale: } \\
\hline Attitudes & 179 & 65.89 & 11.21 \\
\hline Perceived Behavioral Control & 189 & 28.22 & 5.41 \\
\hline Norms & 191 & 19.32 & 4.78 \\
\hline Intent & 191 & 22.15 & 4.81 \\
\hline Environmental Awareness Scale & 183 & 81.19 & 9.95 \\
\hline Conscientiousness About Environment & 192 & 4.73 & 1.46 \\
\hline Involvement in Environment & 192 & 4.33 & 1.32 \\
\hline
\end{tabular}

Table 5. Results of the Multiple Regression Analysis by the dependent variables environmental awareness, involvement, and conscientiousness

\begin{tabular}{|c|c|c|c|c|c|c|c|}
\hline Variable & $\mathrm{t}$ & $\mathrm{p}$ & $\beta$ & $\mathrm{F}$ & df & $\mathrm{p}$ & adj. $R^{2}$ \\
\hline EAS & & & & 14.878 & 6,169 & .001 & .35 \\
\hline believe & 5.187 & .001 & .511 & & & & \\
\hline behcontl & -.812 & .418 & -072 & & & & \\
\hline norms & .395 & .693 & .028 & & & & \\
\hline intent & .248 & ,894 & .024 & & & & \\
\hline sex & -4.766 & .001 & -.301 & & & & \\
\hline age cat & 2.492 & .014 & .156 & & & & \\
\hline & & & & & & & \\
\hline Involved & & & & 4.581 & 4,172 & .002 & .096 \\
\hline believe & .529 & .598 & .061 & & & & \\
\hline behcontl & .092 & .927 & .009 & & & & \\
\hline norms & -.026 & .979 & -.002 & & & & \\
\hline intent & 2.256 & .025 & .256 & & & & \\
\hline & & & & & & & \\
\hline Conscient & & & & 4.397 & 4,172 & .002 & .093 \\
\hline believe & 1.821 & .070 & .209 & & & & \\
\hline behcontl & 1.017 & .310 & .104 & & & & \\
\hline norms & -1.217 & .225 & -.100 & & & & \\
\hline intent & .490 & .625 & .056 & & & & \\
\hline
\end{tabular}




\section{Discussion}

Hypotheses for this study were partially confirmed. Higher scores on the social justice measure were statistically significant predictors of all three of the environmental measures of awareness (EAS), conscientiousness, and involvement in environmental issues. The demographic variable of sex was statistically significantly associated with the EAS and there was a statistically significant interaction of age and sex such that there was a tendency for older females to be more environmentally aware than younger females and all males. The demographic variables of race/ethnicity, religious affiliation (Catholic or not), and college major (psychology or not) were not associated with higher scores on any of the environmental measures. Magnitude of one's religious beliefs was associated with the SJS subscales of perceived behavioral control and norms. The items in the perceived behavioral control subscale have to do with working with, influencing, and having an impact on others. Perhaps students who have a stronger commitment to their personal religious beliefs are also more convinced of their ability to make a difference in the lives of others when it comes to issues involving social justice. The norms subscale has to do with being around others who are committed to social justice issues. Perhaps students who are committed to social justice initiatives are more likely to associate with others who have similar beliefs.

The overall findings of this research are important because if students are sensitive to environmental issues directly related to their own personal experience, this may translate to not only more locally responsible environmental behaviors but also more sensitive global responses to environmental issues, as it has been suggested that individuals contextualize environmental concerns and view global issues in a local context [26]. Turning temporary actions into permanent beliefs about, and commit to, environmental awareness is necessary if behavior change is to become a permanent feature of behavior. Linking social justice beliefs with environmental concerns may be one method of making environmentally friendly behaviors more permanent as these two factors appeared to be associated with each other for students in our sample. Teaching about social justice may make it easier to encourage student involvement in environmental concerns.

It is not surprising that students attending a private Catholic university would endorse social justice values. However, the role of social justice awareness to environmental attitudes has not been fully examined in the research literature. In order to bring about the kind of awareness among young people that will result in concerns for environmental issues, efforts must focus on making these issues meaningful to young adults. Concentrating on increasing awareness of changes one can make in the immediate environment may boost the probability that attitudes and behaviors about environmental issues in general will change for the better. Linking environmental issues to social justice beliefs may prove effective for these students who may already be aware of other human rights dilemmas and also aware of Pope Francis' teachings about the environment.

It was somewhat surprising that few of the demographic variables were predictive of scores on the environmental measures. However, the sample in this study was fairly homogenous (largely female, traditionally religious and from fairly privileged backgrounds), though there was considerable ethnic diversity. The scales were all positively skewed, indicating a tendency for participants to be higher than average on both measures of social justice and measures of environmental awareness at the onset of the research.

Limitations of the study are primarily associated with the select nature of the sample. Gender could not be fully examined because the sample was so heavily female (77.6\%). Students who attend a religious university are more likely to be religious themselves and to also be more concerned about social justice issues, and this may produce differences in responses compared to students at secular colleges. Magnitude of religious beliefs had a low but statistically significant correlation with the perceived behavioral control and norms subscales of the SJS $(\underline{r}=.228, \underline{p}<.01$ and $\underline{r}=.202$, $\mathrm{p}<.01$ respectively, but there were no statistically significant correlations with any of the other social justice subscales or with the environmental measures. Therefore, how religious one reported oneself to be in general did not appear to be a critical factor in beliefs about social justice or about how committed one was to the environment, at least in this study.

Future research should explore the relationship between social justice beliefs and environmental concerns and beliefs among young people at secular colleges. If environmental efforts are to succeed, those individuals at the forefront of social change, such as current college students, must be recruited to the effort. Changing behaviors require an understanding of the attitudes and beliefs of the individuals involved. Making environmental issues meaningful to young people appears to be at the heart of initiating these endeavors. It is often easy to get someone to respond to a temporary environmental initiative such as beach clean-up. However, it is critical that behavior change occur at a more permanent level so that it is maintained over time. Understanding not just what affects behaviors, but what causes long-term changes in attitudes is the critical component necessary if environmental behaviors are going to change for the better over the long-term. Commitment to social justice as it applies to environmental change may be one method of producing more meaningful and permanent changes in environmentally-friendly behavior among young people.

\section{REFERENCES}

[1] Vasquez, M.J.T. (2012). Psychology and social justice. American Psychologist, 67(5), 337-346. 
[2] Byrka, K., Hartig, T., \& Kaiser, F.G. (2010). Environmental attitudes as a mediator of the relationship between psychological restoration in nature and self-reported ecological behavior. Psychological Reports, 107(3), 847-859.

[3] Cackowski, J. M. \& Nasar, J. L. (2003). The restorative effect of roadside vegetation. Environment and Behavior, 35(6), 736-751.

[4] Hartig, T. (2007). Three steps to understanding restorative environments as health resources. In C. Ward-Thompson \& P. Travlou (Eds.). Open space. New York: Taylor and Francis.

[5] Hartig, T., Böök, A., Garvill, J., Olsson, T., \& Gärling, T. (1996). Environmental influences on psychological restoration. Scandinavian Journal of Psychology, 37(4), 378-393.

[6] Jaffe, E. (2010). This side of paradise: Discovering why the human mind needs nature. Observer, 23, 10-15.

[7] Kuo, F. E., \& Sullivan, W.C. (2001). Aggression and violence in the inner city: Effects of environment via mental fatigue. Environment and Behavior, 33(4), 543-571.

[8] Parsons, R., Tassinary, L. G., Ulrich, R. S., Hebl, M. R., \& Grossman-Alexander, M. (1998). The view from the road: Implications for stress recovery and immunization. Journal of Environmental Psychology, 18(2), 113-139.

[9] Taylor, A. F., Kuo, F. E., \& Sullivan, W.C. (2002). Views of nature and self-discipline: Evidence from inner city children. Journal of Environmental Psychology, 22(1-2), 49-63.

[10] Ulrich, R.S. (1984). View through a window may influence recovery from surgery. Science, 224(2), 420-421.

[11] Brown, D., Tuana, N., Averill, M., Baer, P., Born, R., Brandão, C.E.L., Froderman, R., Hogenhuis, C., Heyd, T., Lemons, J., McKinstry, R., Lutes, M., Müller, B., Miguez, J.D.G., Munasinghe, M., de Araujo, M.S.M., Nobre, C., Ott, K., Paavola, J., de Campos, C. P., Rosa, L.P., Rosale, J., Rose, A. Wells, E., \& Westra, L. (2006). White paper on the ethical dimensions of climate change, Report presented at the United Nations Climate Change Conference, Nairobi, Kenya. Retrieved from http://www.ndsciencehumanitiespolicy.org. http://www.guardian.co.uk/environment/cif-een/2009/oct/26 /psychology-of-climate change.

[12] Downey, L., \& Van Willigen, M. (2005). Environmental stressors: The mental health impacts of living near industrial activity. Journal of Health and Human Behavior, 46(3), 289-305.

[13] Pelletier, L. G., Lavergne, K. J., \& Sharp, E.C. (2008).
Environmental psychology and sustainability: Comments on topics important for our future. Canadian Psychology, 49(4), 304-308.

[14] Segalowitz, S. J. (2008). Public health, brain health, and the dangers of air pollution for neural development. Brain and Cognition, 68(2), 115-116.

[15] Swim, J.K., Stern, P.C., Doherty, T.J., Clayton, S., Reser, J.P., Weber, E. U., Gifford, R., \& Howard, G.S. (2011). Psychology's contributions to understanding and addressing global climate change. American Psychologist, 6(4), 241-250.

[16] Corner, A. (October, 2009). Psychology is the missing link in the climate change debate.Retrieved from http://www.guardian.co.uk/environment/cif-een/2009/oct/26 /psychology-of-climate change.

[17] Wang, T. H., \& Katzev, R.D. Group commitment and resource conservation: Two field experiments on promoting recycling. Journal of Applied Social Psychology, 20(4, pt 1), $265-275$.

[18] Arbuthnot, J (1977). The roles of attitudinal and personality variables in the prediction of environmental behavior and knowledge. Environment and Behavior, 9(2), 217-232.

[19] Arbuthnot, J. 1974). Environmental knowledge and recycling behavior as a function of attitudes and personality characteristics. Personality and Social Psychology Bulletin, $1(1), 119-121$.

[20] Borden, R.J., \& Francis, J.L. (1978). Who care about ecology? Personality and sex differences in environmental concerns. Journal of Personality, 46(1), 190-203.

[21] Liarakou, G., Kostelou, E., \& Gavrilakis, C. (2011). Environmental volunteers: Factors influencing their involvement in environmental action. Environmental Education Research, 17(5), 651-673.

[22] Akin, J. (June 18, 2015). Pope Francis's environmental encyclical: 13 things to know. Retrieved from: http://www.catholic.com/blog/jimmy-akin/pope-francis\%E2 $\% 80 \% 99$ s-environmental-encyclical-13-things-to-know-and -share

[23] Brumagim, A. L. (2012). A framework for teaching social and environmental sustainability to undergraduate business majors. Journal of Education for Business, 87, 303-308.

[24] Office of Environmental Policy, University of Connecticut (2012). Environmental Awareness Scale. Retrieved from http://www.ecohusky.uconn.edu/envawareness.html. 